\title{
Adaptation of Board Members to Repeated Failure or Success by their Organization ${ }^{1}$
}

\author{
Alvin Zander, John Forward, and Rosita Albert \\ Research Center for Group Dynamics, The University of Michigan
}

\begin{abstract}
The views of United Fund board members toward goal setting and goal achievement in their organization are examined. Half of the respondents are from Funds with repeated failures during four years, the other half from Funds with successful records during that time. Within each of the Funds approximately half of the respondents are central members of their boards and half are peripheral members. The data are from mailed questionnaires. Contrasting responses by members in successful and unsuccessful Funds suggest that success prepares the ground for future success, and failure for future failure. Central board members, compared to peripheral members, are more deeply involved in the processes of goal setting and in the consequences of their organizations' performance.
\end{abstract}

In many organizations in many parts of society a small group must decide what goal among a set of alternatives arrayed along a scale of difficulty the organization will establish for its members. The goal setters choose an objective they believe will guide and stimulate the efforts of people in the larger body, take care that the goal is not too difficult or too easy, and change the goal as this becomes necessary. There is much to be learned about why a goal-setting committee selects a particular level of difficulty. To study such matters we need information about the origins of goals in a number of groups. United Fund organizations serving many communities in this country present an excellent opportunity for such

${ }^{1}$ Financed by a grant-in-aid to the School of Public Health, The University of Michigan, from the U. S. Public Health Service and by a contract with the Research Center for Group Dynamics made by the Office of Scientific Research, U. S. Air Force.

We are grateful for the advice provided by Arthur Jette and Kenneth Wood, United Community Funds and Councils of America; Robert Kerschbaum, United Fund and Community Services, Ann Arbor, Michigan; Edward Krupat and Lawrence Mohr, The University of Michigan.

A more detailed report of this study, written for Executive Directors of United Funds, is available from the Institute for Social Research, Ann Arbor, Michigan. Title: Motives and satisfactions of United Fund board members, 1968, 67 pp., mimeographed. Price: $\$ 1.00$. 
study. Each Fund has a goal selected by a committee, measures its progress toward that end, and again choses a goal, annually.

Several years ago, Zander and Newcomb (1967) examined the campaign goals and the amounts raised in United Funds of 149 towns during each of four years. ${ }^{2}$ Several results of that inquiry stimulated the present investigation. A Fund that often failed to reach its campaign goal, compared to a Fund that usually succeeded: (a) set its future goal a greater distance above its past level of performance; (b) made this discrepancy larger as the most recent performance was poorer; (c) changed the level of the goal a smaller amount from one year to the next; and (d) showed less improvement in performance as the distance between past performance and future goal was increased.

We conclude from these results that a number of Funds fail and fail again but do not lower their goal to a level that will make failure less likely in the future. Apparently it is more acceptable to fail than it is to lower the goal. This conclusion interested us because members of groups in the laboratory usually will lower the level of the group's goal in order to prevent a future failure (Zander, 1968). Why did goal-setters in United Funds act differently? The research described in the present report was designed to answer this and several related questions. The data are responses of board members in a number of Funds, chosen either because their Fund had repeatedly been successful in attaining its campaign goal or because it had consistently failed to do so in recent years.

The fact that failing funds set their goal too high suggests that board members in those towns were pressed to choose a difficult goal. Indeed, an official goal is a matter of interest to many persons, inside and outside the goal-setting group, most of whom can be expected to put greater value on larger budgets. There is virtually no upper limit to the amount these interested persons may see as desirable, but there is some lower limit below which they would not want the budget to fall. As a result they may offer stronger restraints against lowering a goal than they do against raising it. Such pressures on a decision-making subgroup are doubtless a fact of organization life. There is evidence, moreover, that members of a group in the laboratory can be induced by external agents to choose group aspirations that are either too hard or too easy in the light of previous scores obtained by the group (Zander, 1968).

Our recognition that goal-setters may have been exposed to social pressures when selecting their campaign goal raises other questions. Are

\footnotetext{
${ }^{2}$ Five types of towns were observed with $N$ about 30 in each type: those with 4 successes and no failures, those with 3 successes and 1 failure, those with 2 successes and 2 failures, those with 1 success and 3 failures, and those with no successes and 4 failures.
} 
members in a failing Fund aware that their goal is unreasonable? If so, why do they set it at that level? How do board members react to the performance of their Fund? Do those in failing Funds lose pride in their group? Is success important to them or do they employ some other criterion to judge their Fund's quality of performance?

In the previous study by Zander and Newcomb it appeared that many communities annually repeated a cycle of failure, poor morale, poor performance, and continued failure; but we could not be certain of this since the only available data were from statistical records. In the present investigation we seek to determine if this cycle in fact occurs and, if so, why it occurs, by obtaining information directly from those who oversee these Funds.

\section{Position on the BoArd}

In any organization some members are more responsible than others for how well it performs. This is because the positions they occupy and the duties they enact have direct consequences for the progress of the organization toward its goal. Board members in a United Fund, we assume, are reasonably similar in their personal ability to take responsibility; some of them however exercise more initiative and make more decisions than their colleagues, thus their actions largely determine the fate of the Fund. We shall refer to those whose actions have more impact on the outcome of the Fund as central members; those who have more marginal roles, as peripheral members. The results of prior research demonstrate that central members in a group, compared to peripheral members, develop a stronger desire to have their group achieve success, are more ready to view favorable or unfavorable consequences for the group as the result of their own efforts, and have greater influence on events that lead to these consequences (Pepitone, 1952; Medow and Zander, 1965; Zander and Forward, 1968). How will central and peripheral members differ in their responses to the questions listed above?

Our interest, then is in the views of several types of UF board members. Within each of the successful towns half of the respondents are central persons and half are peripheral; in the failing towns again half of the board members are of each type. Thus, there are four categories of respondents selected on the basis of criteria external to the answers they provided in their questionnaires: successful-central, successfulperipheral, failure-central, and failure-peripheral.

\section{METHOD}

With the help of the Directory published by the United Community Funds and Councils of America in 1964, 1965, 1966, and 1967, we identi- 
fied a number of communities with consistent records of either success or failure during those years. Each annual Directory contains the name of each community with a United Fund, its population, the goal of the year's campaign, and the amount raised in that campaign. The towns we studied were all in the range between 60,000 and 110,000 in population. First, 32 communities were identified (all that could be found) with four failures in a sequence. Second, additional towns were selected that had had four successes in a row (there were over 60 of these) and from these 32 were chosen, each of which was closely matched to one of the failing towns in population and Effective Buying Income (EBI). The EBI is a summary index of financial data from each community, reported annually by Sales Management Magazine, describing the total amount of money available in the community for consumer purchases. For the present purposes the EBI is taken to be an indication of the amount of wealth in the community. Thus, 64 towns were chosen for participation in the study -32 pairs of matched communities.

Eight questionnaires were sent to the professional person in each Fund, called the Executive Director, in each of these 64 communities just prior to the beginning of the annual financial campaign, with a letter from Mr. Lyman Ford, National Executive Director of the UCFCA supporting our request. The local Director was asked to give four of the questionnaires to central members of his board and the other four to peripheral members. Eighteen Executive Directors replied that they were unable to participate. Thus, the number of towns in which board members were given the questionnaires was 46 ; of these 23 were towns with successful records and 23 were towns with failing records. The 23 pairs of towns, analyses revealed, were as closely matched in population and EBI as those in the original, larger, sample.

By the deadline for receipt of the questionnaires, a total of 255 had been received. This is 70 per cent of the 368 actually given to potential respondents. The number of questionnaires from respondents in each of the four categories is as follows:

\begin{tabular}{|c|c|}
\hline Category & $N$ of respondents \\
\hline Success-central & 70 \\
\hline Success-peripheral & 60 \\
\hline Failure-central & 67 \\
\hline Failure-peripheral & 58 \\
\hline & 255 \\
\hline
\end{tabular}

The letter to the Executive Director did not inform him that the success or failure of his recent campaigns was an important factor in selecting his associates for study because we believed that such informa- 
tion might embarrass him when he handed the questionnaire to a member of his board and because we did not wish to have the board member aware that this was a major interest of the investigation. The letter provided the following statement to help the Director identify central and peripheral members.

"There is good reason to believe that the opinions and feelings of group members differ as they are more or less central in the work of the group. We ask, therefore, that four of the eight Board members you select be persons who have central positions and that four have peripheral positions. A central person is one who has accepted responsible jobs for the Board, has performed them reliably, has a deep interest in the fortunes of the UF, or in other ways has been strongly involved. He may be a present or past officer of the Board but he need not be. Your judgment is the best guide here. A peripheral person is one who has held few or no responsible jobs for the Board, has shown less interest in its work, or in general has not become greatly involved. These people will tend to be newer members of the Board, which is acceptable to us, but we would prefer, if they are available, to have such persons be those who have had one or two years experience on the Board so that they are not wholly unfamiliar with the Board's work.

"You will note that four of the eight forms enclosed are marked with a letter $\mathrm{A}$ and the other four with the letter $\mathrm{B}$. Please give the $\mathrm{A}$ forms to the four more central persons, as you judge them, and the $B$ forms to the four more peripheral persons. The $\mathrm{A}$ and $\mathrm{B}$ forms are the same. The letters are simply a convenient way for you to let us know how you see them."

A letter attached to the board member's questionnaire contained the following statement about the purposes of the study: "This is a study of United Fund board members in medium-sized cities. It is one of many similar studies made by research teams for The University of Michigan. The main purpose of these studies is to learn how different types of organizations operate, what makes an organization a good one to work for, and why people work for it." The questions were all five-point, Likert-type rating scales (one is low and five is high). The respondent was asked not to sign his form and to return it directly to the authors in an envelope provided for that purpose.

The average characteristics of the respondents differ to a statistically reliable degree in ways that fit our request. Central board members, compared to peripheral ones, are somewhat older, have held more offices on the board, have been members of the budget committee (the group responsible for recommending the campaign goal to the board), and occupy more prestigeful jobs in the community. Over half of the central persons but only one-fifth of the peripheral members have been on the board for more than five years. The central and peripheral members do not differ in their amount of formal education (almost all are college graduates) or in their role in the solicitation of funds. 
There were no significant differences in the characteristics of board members in successful towns compared to those in failing ones, except that members in failing Funds (both centrals and peripherals) more often than those in successful Funds, had leadership roles in the campaign that was to begin soon.

Statistical treatment of the results was done by analysis of variance.

\section{RESULTS}

\section{Sources of Satisfaction for Board Members}

The potential attainment of a future goal promises particular consequences for the goal-seekers. These consequences, we assume, are the members' incentives for participation in the organization. On the basis of advice from informants who have been UF board members we inquired about five. These are listed in Table 1. The respondent was asked: If, or when, your community raises enough money, reaches its goal, and has a success, what might contribute most to your sense of satisfaction from such an event? He was to rank-order the five alternatives.

TABLE 1

Sources of Satrsfaction from Successfut Campaigns

\begin{tabular}{lc}
\hline & $\begin{array}{c}\text { Average rank order } \\
\text { all respondents }\end{array}$ \\
\hline Welfare needs of community can be met & 1.38 \\
Knowing that our UF is a successful organization & 2.39 \\
Community will be approved for doing a good job & 3.09 \\
Personally working hard on my part to help achieve goal & 3.46 \\
The community will approve of my efforts & 4.64 \\
\hline
\end{tabular}

We observe in the Table that satisfaction from meeting the welfare needs of the community is given the highest ranking by respondents, having the Fund be successful as an organization is next most satisfying and personal gain from the Fund's success is least satisfying. The source of satisfaction ranking first, meeting the needs of the community, is significantly more important to central members than to peripheral ones $(p<.05)$. The source of satisfaction ranking second, successful performance of the organization, is more important among those central board members who perceive themselves to be more active in behalf of the Fund (as indicated by responses to a question shown in Table 8) than for those peripheral members who are most inactive in their effort for the Fund $(p<.05)$, and the source of satisfaction ranking fourth, satisfaction with own efforts, is more important to the highly active central persons in successful towns than in failing ones $(p<.05)$. 
It is evident that members of the board see their major mission to be the providing of funds for the programs of local welfare agencies and that central members believe this more strongly than do peripheral members. There were no notable differences between successful and unsuccessful board members in their rankings of these items.

\section{Levelis of Performance and Campatgn Goals}

Even though members of the boards in succeeding and failing towns have similar purposes, their Funds show marked differences in specific goals and levels of performance, replicating results previously reported by Zander and Newcomb (1967). The campaign goals and the amounts raised were taken from the UCFCA Directories. The averages for successful and failing Funds are shown in Table 2.

TABLE 2

Average Campaign Goals and Levels of Performance, Three Campaignsa

\begin{tabular}{lccc}
\hline & Succeeded & Failed & $\begin{array}{c}\text { Reliable } \\
\text { differences }\end{array}$ \\
\hline Mn. amt. raised per capita & $\$ 4.72$ & $\$ 2.99$ & $\mathrm{~S}>\mathrm{F}^{* * *}$ \\
Mn. income/EBI & .22 & .14 & $\mathrm{~S}>\mathrm{F}^{* * *}$ \\
Mn. difficulty of goal: goal level/EBI & .20 & .15 & $\mathrm{~S}>\mathrm{F}^{* *}$ \\
Mn. per cent increase in income & $9.00 \%$ & $5.90 \%$ & - \\
$\begin{array}{l}\text { Mn. per cent campaign goal exceeded prior } \\
\text { year's income }\end{array}$ & $5.92 \%$ & $17.76 \%$ & $\mathrm{~F}>\mathrm{S}^{* * * *}$ \\
Mn. per cent of official goal actually raised & $102.72 \%$ & $90.19 \%$ & $\mathrm{~S}>\mathrm{F}^{* * *}$ \\
Mn. per cent that goal for 1968 campaign & $5.80 \%$ & $18.18 \%$ & $\mathrm{~F}>\mathrm{S}^{*}$ \\
$\quad$ exceeded income in 1967 & & & \\
\hline
\end{tabular}

${ }^{a}$ From UCFCA records, 1965-67.

$* p<.05$.

${ }^{* *} p<.025$.

$* * * *<.01$.

$* * * * *<.001$.

Successful Funds solicited more income per capita than failing Funds during these years. The successful Funds also raised a larger proportion of the wealth available to citizens (amount raised divided by EBI) and set more difficult goals (level of goal divided by EBI). In failing towns, however, the board placed the official goal for each new campaign a greater distance above the income solicited the previous year (the $D$-score) than the board did in succeeding towns. The proportion of the goal raised was therefore smaller in failing Funds than in succeeding ones; the proportion of improvement in amount raised from one year to the next however was not significantly different in failing compared to successful Funds. 
Thus, the failing Funds did not perform as well as succeeding ones; the goals they failed to reach were less difficult than the goals of the succeeding Funds, yet these goals were unreasonably high in the light of their past levels of performance.

Estimates of Future Success. At the time the respondents filled-in their questionnaires their organizations had established a goal for the 1968 campaign (to be held in the fall of 1967) but solicitation had not yet begun. It was possible then for us to inquire about plans for the 1968 campaign and, months later, to determine from the UCFCA records how well their Fund had met that goal. The discrepancy between the official goal (for 1968) and the level of performance in the prior year was again larger in the failing Funds than in the successful ones $(p<.01)$, and the former usually failed to attain their goals while the latter typically reached them $(p<.05)$.

We asked respondents what (as they recall it) is the official goal for the campaign that was to occur in a few weeks. On the average, the goal they recalled was not significantly different from the official goal. We also asked if they personally believed that the community's goal was at the best possible level. All but a handful said, Yes, the goal was a most satisfactory one. Thus, they knew the goal and were inclined to accept it.

This question followed: What per cent of the 1968 goal do you estimate the town will raise? Those in the failing communities were significantly less confident than those in the succeeding towns that they would achieve their goal $(p<.001)$. A question less constrained by realism was also offered: If the campaign were run as well as possible, what is the largest amount you think could possibly be raised in your community? Those in failing Funds were strikingly more optimistic than those in succeeding towns: in failing towns they estimated that they could exceed the goal by $15 \%$ and in succeeding towns by $8 \%$ under ideal conditions $(p<.05)$.

Central members were more confident that the Fund would reach its 1968 goal $(p<.05)$ and were more optimistic that it could ideally exceed its goal, than were peripheral members $(p<.025)$.

To summarize, participants' estimates of future success were largely in accord with past goals and levels of performance in their local Funds.

\section{Attitudes toward the Level of Campaign Goals}

We have observed that the majority believed the goal for the 1968 campaign to be the best possible one. How do they feel about the goals their Fund has previously chosen? Do they wish their goals had been easier or harder?

The respondents were invited to answer the following: All things 
considered, in your private judgment, have your town's goals in the last. few years tended to be too high or too low? The answers in Table 3 reveal that the men in successful towns say these goals have been a bit too low while those in failing Funds say they have been about right.

TABLE 3

Average Attitudes toward Level of Campaign Goal

\begin{tabular}{|c|c|c|c|c|c|}
\hline & \multicolumn{2}{|c|}{ Succeeded } & \multicolumn{2}{|c|}{ Failed } & \multirow{2}{*}{$\begin{array}{c}\text { Reliable } \\
\text { differences }\end{array}$} \\
\hline & Central & Peripheral & Central & Peripheral & \\
\hline Past goals too high or too low? ${ }^{a}$ & 2.74 & 2.97 & 3.05 & 3.14 & $\mathrm{~F}>\mathrm{S}^{* *}$ \\
\hline $\begin{array}{l}\text { Willingness to lower UF cam- } \\
\text { paign goal after failure? }\end{array}$ & 2.03 & 2.12 & 2.21 & 2.37 & - \\
\hline $\begin{array}{l}\text { Effectiveness of lowering goal } \\
\text { in ensuring success? }\end{array}$ & 2.23 & 2.12 & 2.20 & 2.56 & $\mathrm{FP}>\mathrm{FC}^{*}$ \\
\hline $\begin{array}{l}\text { Difficulty of lowering goal after } \\
\text { failure? }\end{array}$ & 2.75 & 2.85 & 2.94 & 2.48 & $\mathrm{FC}>\mathrm{FP}^{*}$ \\
\hline
\end{tabular}

${ }^{a}$ Scale: $2=$ a bit too low, $3=$ about right, $4=$ a bit too high.

$* p<.05$.

$* * p<.025$.

We have seen that Funds tend to raise their future goals, or to keep them at the same level, more often than they lower them, regardless of their past successes or failures. Let us focus then upon resistance to lowering the goal after a failure since reasons for raising a goal after success are of less interest.

The respondents were presented with this query: Suppose for the moment that your campaign this fall does not attain the official community goal, and suppose that a proposal is made next year to set a lower goal than the one your community failed to reach this fall, would you be inclined to support this proposal to lower next year's goal? It is evident in the second row of Table 3 that the participants of each type did not differ in their responses; they "probably would not" support this proposal.

At another point in the questionnaire they were asked: If it happened that the campaign goal was not attained this fall, which of the following do you think would best describe your view for next year? They were given three alternatives: (a) set the goal low enough to have a good chance of attaining it, (b) keep the same goal even if we might not be likely to make it next year, or (c) raise the goal some reasonable amount. Only $14 \%$ of the respondents chose response (a), to lower the goal after 
a hypothetical failure, while the remaining $86 \%$ would either keep it the same or raise it. These proportions were similar regardless of the town's previous history of success in UF campaigns or the position of the member on his board. Again, we see little preference for lowering the goal.

Because of their greater responsibility for the success of the Fund, we might expect central members to be more inclined than peripheral members to resist lowering the goal. Observe in Table 3 that central persons (in failing towns) do indeed believe that there is less value in lowering the goal than do peripheral persons and that it also would be more difficult to lower it. It appears that it is the central persons who are most likely to resist lowering the goal for a new campaign following a failure in the previous year.

Sources of Resistance to Lowering of Goals. Clearly there are restraints against lowering the level of next year's goal after a Fund has had an unsuccessful campaign. What pressures do respondents perceive to be acting on them when they are selecting a goal?

Answers to the following questions were asked of those who stated that their Funds had had a failure while they were a member of the board: Concerning the most recent failing campaign, why was the goal set too high? What reasons determined where the goal was set? They were provided seven alternatives and asked to indicate which ones were more likely to account for the selection of an unduly high goal. None of the listed reasons were given high (or even moderately high) ratings. Either the respondents are not certain about why the goal was set too high to attain or they think that reasons other than those offered are more important. Few persons, however, wrote in additional reasons even though they were invited to do so.

The reasons chosen most often as responses to the above question were: that agencies need increases in their budgets, that the goal was incorrectly assumed to be not too high, and that they thought a higher goal would stimulate more giving. There were no noteworthy contrasts among the responses made by persons in separate categories of this study.

A further attempt was made to determine the perceived sources of opposition to lowering of a campaign goal. In this instance, respondents who had indicated that they would oppose lowering of the goal, as noted above, were invited to indicate how important each of a number of reasons might be for their opposition. They were given eight items to consider which, in contrast to those discussed previously, were more concerned with the respondent's personal rationalizations.

Among all respondents the greatest importance was attached to two matters: if the goal was lowered, the Fund would not meet the needs of 
the community, and lowering the goal might make it necessary for separate agencies to solicit their own funds. Once more it is the need of the agencies supported by the Fund which restrains board members from lowering the goal.

Members of the board in towns with a record of failure are not generally different from those with a record of success in their reasons for opposing the lowering of the goal. Central members are different from peripheral ones, however, in two ways that are revealing. Participants in central roles, more than those in marginal positions, oppose lowering of the goal because the board would be avoiding the challenge generated by a difficult task $(p<.05)$ and because the supporters of the agencies would exert pressures on the board for a higher goal $(p<.05)$.

When we limit our attention to respondents in failing towns, the contrasts between central and peripheral persons are different from those just mentioned. The peripheral members, more than the central ones, oppose lowering of the campaign goal because less money would be raised if that were done $(p<.01)$ and because a lowered goal would not allow the Fund to meet the needs of the community $(p<.01)$.

It appears then that a central role, particularly in a successful town, generates interest in meeting a challenge and a sensitivity to pressures from the supporters of the local welfare agencies; while a peripheral role, especially in a failing town, generates an awareness that a lowered goal will cause an inability to meet the needs of the community.

\section{Motivational Consequences and Pride in Group}

Failure in a UF campaign deprives board members of the satisfactions listed in Table 1 and doubtless generates unfavorable consequences for those involved. A success, on the other hand, provides a variety of satisfactions and few unfavorable consequences. A series of failures is perhaps worse than a single losing campaign. How do members of a failing board react to the negative discrepancies between past aspirations and achievements?

Criteria of Success in Campaigns. One way to cope with failure is to decrease the importance of goal achievement as a criterion of success, that is, to derogate the importance attached to attainment of the campaign goal. We see in Table 4 that board members in failing towns attribute less importance to achievement of the campaign goal than do those in successful towns.

If there were no goal there could be no failure; without a goal there could be no success. Will those from towns with records of repeated failure more often prefer that they not establish a goal? Respondents were asked if they agree with the following statement: I think it would 
be good if, somehow, the UF could work toward meeting needs in the community without setting campaign goals at all. In the second row of Table 4 we observe that respondents in failing communities are more inclined to agree with this statement than are those in successful communities.

TABLE 4

Mean Concern about Goals

\begin{tabular}{|c|c|c|c|c|c|}
\hline & \multicolumn{2}{|c|}{ Succeeded } & \multicolumn{2}{|c|}{ Failed } & \multirow{2}{*}{$\begin{array}{c}\text { Reliable } \\
\text { differences }\end{array}$} \\
\hline & Central & Peripheral & Central & Peripheral & \\
\hline $\begin{array}{l}\text { How important that UF attain } \\
\text { campaign goal? }\end{array}$ & 4.73 & 4.53 & 4.45 & 4.45 & $\begin{aligned} \mathrm{S} & >\mathrm{F}^{* *} \\
\mathrm{SC} & >\mathrm{FC}^{* *}\end{aligned}$ \\
\hline $\begin{array}{l}\text { Prefer that UF not set goals } \\
\text { at all }\end{array}$ & 1.97 & 2.14 & 2.32 & 2.67 & $\mathrm{~F}>\mathrm{S}^{*}$ \\
\hline
\end{tabular}

${ }^{*} p<.05$.

${ }^{* *} p<.025$.

A further finding suggests that members in failing Funds prefer not to judge the performance of their agency by its progress toward the official goal. The question was offered: For the coming campaign, which of the following are you likely to use in judging whether it was a success? They were to choose among the three alternatives noted in Table 5. Achievement of the goal was more often favored by succeeding than by failing board members but "doing better than last year" was more often men-

TABLE 5

Proportion Preferring a Given Crimerion of Success

\begin{tabular}{lccccc}
\hline & & Criterion of success & \\
& $\begin{array}{c}\text { Amount raised } \\
\text { exceeds goal }\end{array}$ & $\begin{array}{c}\text { Amount raised } \\
\text { is more than } \\
\text { last year }\end{array}$ & $\begin{array}{c}\text { Amount raised } \\
\text { is more than } \\
\text { privately pre- } \\
\text { ferred goal }\end{array}$ & \\
\hline $\begin{array}{l}\text { Succeeded }(\mathrm{N}=130) \\
\text { Failed }(\mathrm{N}=124)\end{array}$ & $68 \%$ & $24 \%$ & $8 \%$ & $100 \%$ \\
& $48 \%$ & $42 \%$ & $10 \%$ & $100 \%$ \\
\hline
\end{tabular}

tioned by failing board members. Thus, participants in failing towns may get sufficient satisfaction from doing better than last year regardless of whether their intake reaches the official goal.

It seems clear that members of the boards in failing Funds, compared to those in succeeding Funds, are less inclined to take the goal seriously as the end point of their efforts, and as the criterion for success. Central 
and peripheral members do not differ in their willingness to use the campaign goal as a criterion of success.

Evaluation of Fund's performance. Because of their consistent failures and the probable loss of pride in their organization, we expect men in failing Funds to give lower evaluations to their unit than the men in successful Funds. Accordingly, respondents were asked to evaluate the performance of several parts of the UF: the board, the campaign workers, and the effectiveness of the UF as a service to the community. The results in Table 6 reveal that board members in a failing town give lower ratings on these matters than do those in succeeding Funds. It is interesting that members of the board in failing Funds assign lower ratings to the campaign workers than to the board, perhaps they prefer to blame those who work in the campaign rather than those who oversee the organization, their own group.

TABLE 6

Average Evaluatron of Local Fund

\begin{tabular}{|c|c|c|c|c|c|}
\hline & \multicolumn{2}{|c|}{ Succeeded } & \multicolumn{2}{|c|}{ Failed } & \multirow{2}{*}{$\begin{array}{c}\text { Reliable } \\
\text { differences }\end{array}$} \\
\hline & Central & Peripheral & Central & Peripheral & \\
\hline & & & & & $\mathrm{S}>\mathrm{F}^{* * *}$ \\
\hline \multirow{4}{*}{$\begin{array}{l}\text { How well has UF board per- } \\
\text { formed in recent years? } \\
\text { How well local campaign } \\
\text { workers performed? }\end{array}$} & & & & & $\mathrm{P}>\mathrm{C}^{* *}$ \\
\hline & 4.16 & 4.57 & 3.35 & 3.58 & $\mathrm{FP}>\mathrm{FC}^{* *}$ \\
\hline & & & & & $\mathrm{S}>\mathrm{F}^{* * *}$ \\
\hline & 4.16 & 4.42 & 2.70 & 2.98 & $\begin{array}{l}\mathrm{P}>\mathrm{C}^{* *} \\
\mathrm{~S}>\mathrm{F}^{* * * *}\end{array}$ \\
\hline How good is UF type of organi- & & & & & $\mathrm{P}>\mathrm{C}^{* *}$ \\
\hline zation for community needs? & 4.13 & 4.27 & 3.46 & 3.68 & $\mathrm{FP}>\mathrm{FC}^{*}$ \\
\hline
\end{tabular}

$* p<.05$.

${ }^{* *} p<.025$.

$* * * *<<.001$.

Central board members evaluate all three aspects of the Fund lower than do peripheral members. These differences are stronger in failing units than in successful ones. We noted earlier that central members have more optimistic expectations for the Fund than do peripheral members, thus it seems reasonable that they should feel failure more keenly and develop greater loss of pride in their organization when it fails.

The Fund's Performance and Self-Regard. Several questions were put forward, shown in Table 7, to determine the effect of the Fund's past record on a member's evaluation of his personal contribution. It can be seen in the Table that a participant in a failing Fund gives a lower rating to his work on the board than does a participant in a succeeding Fund. 
It is interesting, however, that a Fund's history does not affect his appraisals of how well he helps in the campaign or of how much influence he has in meetings of the board.

TABLE 7

Average Evaluation of Own Performance

\begin{tabular}{|c|c|c|c|c|c|}
\hline & \multicolumn{2}{|c|}{ Succeeded } & \multicolumn{2}{|c|}{ Failed } & \multirow{2}{*}{$\begin{array}{c}\text { Reliable } \\
\text { differences }\end{array}$} \\
\hline & Central & Peripheral & Central & Peripheral & \\
\hline $\begin{array}{l}\text { How well have you per- } \\
\text { formed your part for } \\
\text { board? }\end{array}$ & 3.61 & 3.47 & 3.39 & 2.93 & $\begin{aligned} \mathrm{S} & >\mathrm{F}^{* *} \\
\mathrm{C} & >\mathrm{P}^{* *} \\
\mathrm{FC} & >\mathrm{FP}^{* *}\end{aligned}$ \\
\hline $\begin{array}{l}\text { How well have you per- } \\
\text { formed your part in UF } \\
\text { campaign? }\end{array}$ & 3.61 & 3.53 & 3.53 & 3.46 & - \\
\hline $\begin{array}{l}\text { How much influence do } \\
\text { your opinions have on } \\
\text { UF board? }\end{array}$ & 3.61 & 3.07 & 3.58 & 3.16 & $\begin{aligned} \mathrm{C} & >\mathrm{P}^{* * * * *} \\
\mathrm{FC} & >\mathrm{FP}^{* * * *} \\
\mathrm{SC} & >\mathrm{SP}^{* * * * *}\end{aligned}$ \\
\hline
\end{tabular}

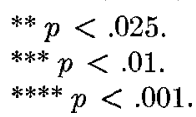

Central members rate their contribution to the board higher than do peripheral persons. Centrals also believe that they have more influence on the board. These self-evaluations appear to be realistic reflections of their stronger and more influential positions in the organization.

We conclude that the past record of the Fund is taken by members to be an indication of how well they personally have performed and that central men have greater pride in their personal effort than do peripheral men.

Work in Behalf of the Fund. We measured their effort, as they saw it, by asking how much work they have put into various activities of the Fund. The responses in Table 8 suggest that board members may work harder for a failing Fund than they do for a succeeding one. Men in failing Funds, more than those in successful ones, believe they put in more time during the weeks of the campaign and work harder than their colleagues do. Members of failing boards furthermore believe that their personal efforts will contribute more to the success of the coming campaign than do those on successful boards. There are no differences, however, between successful and failing towns, in the number of hours members state they devote to work on the board during noncampaign weeks; they are also fairly similar in the belief that the amount of time they devote to work for the UF is about what they should put in. 
We see in Table 8 that central persons believe their efforts will contribute more to the coming campaign, than do peripheral members, and in failing towns that central members claim to put in more hours on the campaign than do peripheral members. Seemingly the hardest working board member is a central person in a failing Fund, during the weeks of the campaign.

TABLE 8

Effort Devoted to United Fund

\begin{tabular}{|c|c|c|c|c|c|}
\hline & \multicolumn{2}{|c|}{ Succeeded } & \multicolumn{2}{|c|}{ Failed } & \multirow{2}{*}{$\begin{array}{c}\text { Reliable } \\
\text { differences }\end{array}$} \\
\hline & Central & Peripheral & Central & Peripheral & \\
\hline $\begin{array}{l}\text { Hours devoted to work for } \\
\text { UF (noncampaign weeks) }\end{array}$ & 4.31 & 4.17 & 4.36 & 4.16 & - \\
\hline $\begin{array}{l}\text { Hours devoted to work for } \\
\text { UF during campaign weeks }\end{array}$ & 4.28 & 4.12 & 7.28 & 5.12 & $\begin{aligned} F & >\mathrm{S}^{* * *} \\
\mathrm{FC} & >\mathrm{FP}^{* *}\end{aligned}$ \\
\hline $\begin{array}{l}\text { Do you put in more or less } \\
\text { time than average member } \\
\text { of board? }{ }^{a}\end{array}$ & 3.78 & 2.78 & 4.06 & 3.04 & $\begin{array}{c}\mathrm{F}>\mathrm{S}^{*} \\
\mathrm{C}>\mathrm{P}^{* * * *}\end{array}$ \\
\hline $\begin{array}{l}\text { Do you put in more or less } \\
\text { time than you should?a }\end{array}$ & 3.04 & 2.88 & 3.03 & 3.02 & - \\
\hline $\begin{array}{l}\text { How important will your } \\
\text { efforts be in coming } \\
\text { campaign? }\end{array}$ & 3.09 & 2.92 & 3.51 & 3.16 & $\begin{aligned} \mathrm{C} & >\mathrm{P}^{*} \\
\mathrm{~F} & >\mathrm{S}^{* * *} \\
\mathrm{FC} & >\mathrm{FP}^{*}\end{aligned}$ \\
\hline
\end{tabular}

${ }^{a}$ Scale: $2=$ a bit less, $3=$ about the right amount, $4=$ a bit more.

${ }^{*} p<.05$.

$* * p<.025$.

$* * * p<.01$.

$* * * * p<.001$.

\section{Perceived Reasons for Fund's Level of Performance}

Several questions, each with many alternatives to be rated, were asked concerning the reasons that a Fund succeeds or fails. The first question was: If, or when, your local Fund has a successful campaign and attains the official goal, how important would each of the following factors be in determining the successful outcome of the campaign? A parallel question was asked and similar alternatives were provided concerning a failing campaign. The ratings assigned to items for both these questions revealed that respondents (regardless of their Fund's past successes or their position on the board) attached most importance to how well the campaign is organized and to the leadership provided by the campaign chairman and the Executive Director.

The responses of members in successful towns and those in failing towns are significantly different, for the first question, in only one 
instance. Those in failing communities are more inclined to attribute success to the strong interest of local citizens in the agencies supported by the Fund $(p<.025)$. Men occupying a central position, more than those in peripheral posts, place greatest weight on the importance of having influential persons in the community favoring the campaign $(p<.01)$ and on the effectiveness of the Executive Director $(p<.05)$. In their responses to the second question, about the reasons for failure, the only notable item is that members in failure Funds, more than those in successful Funds, blame insufficient volunteer help as a cause for failure $(p<.05)$.

The mean ratings of the items in the question concerning failure were subtracted from the mean ratings of the same items as a source of success. When this was done several interesting results appeared. (a) The reasonableness of the goal is cited as a source of success more than the unreasonableness of the goal is cited as a source of failure $(p<.05)$ and centrals believe this more strongly than do peripherals $(p<.05)$. (b) The amount of money citizens have available to them is cited as a source of success more than it is cited as a source of failure $(p<.05)$. (c) The interest of local citizens in UF agencies is cited as a source of success more than it is as a source of failure $(p<.05)$. We conclude that board members, when thinking about sources of success in campaigns, are more alert to the subjective probability of attaining the goal and that these matters are less salient when thinking about sources of failure in campaigns.

One other pair of questions requires only brief mention. The board members were asked how effective certain actions might be in ensuring that the next campaign attains its goal and how difficult these actions might be. The most effective action by far $(p<.01)$ was to obtain more volunteers and this was seen as not very difficult to do, but more difficult in failing towns than in succeeding ones $(p<.05)$. The most difficult action was to hire more staff $(p<0.25)$ and this was seen as likely to be least effective in ensuring a success.

\section{SUMMARY AND DISCUSSION}

We have examined the views of United Fund board members toward goal setting and goal achievement in their organizations. Half of the respondents were selected from Funds who had consistent records of failure during the past four years, the other half from Funds with wholly successful records during the same time. Within each of the failing and succeeding Funds (matched for community size and economic potential), half of the respondents were central members of their boards and half were peripheral members. 
Regardless of the performance record of their Fund or the position they occupy on the board, a successful campaign is satisfying to board members primarily because a success makes it possible for local agencies to have the money they need for their programs. Thus, a board member typically desires that his Fund raise enough to meet the needs of the agencies in the community-the member is satisfied if the needs of others are satisfied. The second ranking source of satisfaction is in the success of his organization, thereby presumably providing a sense of pride in his organization.

The respondents are fairly uniform in their willingness to raise goals and in their resistance against lowering goals. They say they resist lowering their Fund's aspirations because the needs of the agencies in the community would not be met and separate agencies might run their own financial campaigns if the goals were lowered. Respondents do not differ in their adherence to the psychology of the "asking price." That is, they believe that a higher goal stimulates contributors to give larger amounts.

\section{The Crcle of Events in Failing Towns}

The significant differences in the responses of board members in successful and unsuccessful Funds can be summarized under several generalizations, ignoring for the moment whether the responses are by a central or a peripheral person.

1. Assuming that the goal of a campaign is an accurate indication of budget needs in local agencies, failing Funds, by definition, are not meeting these needs.

Even though their goals are set at an easier level (considering the wealth of local citizens), failing Funds, compared to succeeding Funds, take in less per capita and solicit a smaller proportion of the official campaign goal.

2. Board members in failing Funds react to their lack of success by setting higher goals than are warranted by their prior levels of performance. This larger discrepancy between their past levels of performance and their future goals is fostered by several conditions which become more salient to those in failing Funds than to those in succeeding ones.

Despite the smaller amount of money they solicit per capita, members in failing Funds express a greater dislike for lowering the goal after a failure and are unwilling to support any proposal to that effect. Those in failing Funds appear to be more conscious of the needs of the community and place more pressure on themselves to meet those needs. They also state that there is less value in lowering the goal after a failed campaign and more strongly believe that it would be difficult to do so. Board members of failing Funds, in short, seem to be more concerned (with good 
reason) about the needs of the local welfare agencies than are those in succeeding Funds and apparently allow the goal to be more determined by such matters than by an appraisal of what the Fund can reasonably be expected to raise.

3. The respondents from failing Funds reveal in their answers that the failures have been accompanied by unfavorable consequences.

Members of failing boards, compared to those of succeeding boards, have less pride in their organization, rate their own personal contribution lower, blame the campaign workers rather than the board for a poor campaign (even though they themselves are likely to have worked on the campaign), blame lack of volunteers as the cause of a poor campaign, state they have difficulty in recruiting volunteers, and believe they work harder than colleagues in the Fund. Too few men are doing more, and enjoying it less.

4. The respondents from failing Funds attach less importance to goal achievement as a criterion of success.

Board members in failing Funds, more than members in succeeding Funds, think attainment of the goal is less important, work as often to beat last year's level of performance as to attain the goal, and would like to do away with goals altogether. They are less confident moreover that they can attain the goal for the 1968 campaign.

5. The foregoing characteristics are not only the result of failure, they also contribute to less efficient campaigns and, given the tendency of failing Funds to set unreasonably difficult goals, these inefficient efforts create a strong likelihood of repeated failure.

The five generalizations form a sequence-a circular one. They suggest that failure may prepare the ground for further failure and that success may lead to further success, all else equal.

The central issue remains, why did boards of failing Funds set their goals so far above past levels of performance? The available data do not provide an unequivocal answer to this question but they suggest that several influences may be at work.

(a) Board members in failing Funds, become more vulnerable to social influence arising outside their organizations. Thus, the legitimate needs of the agencies, which they have failed to meet in some degree, become more salient to those in failing Funds than to those in succeeding ones. The need for money is naturally greater than the amount the Fund has raised and the goal is therefore fixed at the level of that need. The results of laboratory experiments support this view: groups that fail to attain their goal are more readily influenced by external agents to set a higher goal than are groups that achieve success (Zander, 1968).

(b) Boards in failing Funds become concerned to avoid unfavora- 
ble consequences such as embarrassment, loss of pride in group, or disapproval by citizens in the community. The concern with avoiding these unfavorable aspects of group evaluation outweighs their tendency to select a goal that is realistically a challenge yet attainable. They perceive that a failure on a difficult goal is less embarrassing than a failure on an easy goal and they therefore choose an unreasonably difficult goal. Results of research in the laboratory support this view.

(c) A higher goal, members of the board believe, will solicit larger contributions from givers. The results from the present study and the one by Zander and Newcomb (1967) indicate that this belief is not always valid. A goal can be too difficult.

\section{Effects of Central and Peripheral Positions}

A person with a more central position, we have assumed, becomes aware that he is more responsible for the outcome of the Fund's work. We first review the responses of central and peripheral members regardless of whether they are in successful or unsuccessful towns.

Central and Peripheral Board Members. Central board members, more than peripheral members, are satisfied when their Fund achieves its campaign goal because this achievement, they say, ensures that needs of the community will be met, and because they can take pride in their organization. The occupants of central positions display greater confidence in the future of the Fund than those in less responsible posts: they predict that the Fund will solicit as much as it sets out to obtain and they believe that under ideal conditions it could exceed the official goal.

Very few of the board members, we have seen, like to lower the campaign goal from one year to the next, however, centrals offer reasons for their opposition which reflect the nature of their role. Centrals do not wish to lower the goal since this would be running away from a challenge and because the supporters of the local agencies would press the Fund (and the central persons) for a higher goal.

Centrals, compared to peripherals, give lower evaluations to the board, to the campaign workers, and to the UF as an organization, and they believe that they work harder than anyone else on the board. They recognize that their influence on the board is high, and that their efforts will be important for the success of the 1968 campaign.

Central and Peripheral Members in Successful Towns. When their Fund has been consistently successful, central board members derive greater satisfaction than peripheral members from the effective operation of their organization. They believe that a campaign goal might be set too high because of a mistake in planning but not because agencies make 
unreasonable demands. Centrals recognize that lowering the campaign goal would arouse social pressure in opposition to such a move and oppose lowering of the goal since this avoids a challenge. Central members are more disposed to obtain satisfaction from successful outcomes of their personal efforts on the board. More than peripherals, they believe that the goal must be a reasonable one in order to ensure success in the campaign, that the leadership of the Fund must be effective, and that the support of influential citizens in the community must be obtained.

In a successful town, then, centrals, more than peripherals, derive greater satisfaction from their effort, and believe that success is assured if the goal is reasonable, the campaign is well run, and if the support of influential citizens is obtained.

Central and Peripheral Members in Failing Towns. When their Fund has had a series of failing campaigns, central and peripheral members are sharply different in their views about the proper level of the goal. Centrals say that the goal was set too high because the agencies made high demands and because it would be difficult to lower the goals. Centrals, more than peripherals, do not believe that lowering the goal would do much to ensure success anyway; citizens must be interested in supporting welfare agencies if the Fund is to have a successful campaign. Central board members, compared to peripheral members, put in more time working for the Fund, devote more time during the weeks of the campaign, and believe their personal efforts will be more important in determining the success of the 1968 campaign.

To summarize, central members in failing towns believe the goal is placed at a high level because of the pressures on the board to put it there; lowering the goal, furthermore, would not ensure success because a success requires more interest among the citizens and more sharing of the work to be done.

In a failing Fund, compared to a succeeding one, a central person strongly feels obliged, and pressed, to set high goals and to work hard toward those ends even if he must do most of the work himself.

The annual cycle of events in a United Fund is a reasonable analogue of the steps followed in a typical laboratory experiment on level of aspiration: a performance is followed by the setting of a goal, another performance, another setting of a goal, and so on. It is interesting that behavior in the laboratory is fairly well replicated in the United Funds, suggesting that level of aspiration theory may be used to explain phenomena associated with the choice of organizational goals, where these latter are arrayed along a scale of difficulty.

The results of the study described in this report also indicate, however, that usual theoretical notions concerning aspiration levels will need to be 
supplemented when attempting to understand the aspirations of groups, especially those outside the laboratory. It seems clear, for example, that the motives to achieve success and to avoid failure, most frequently taken to be major determinants of the aspiration level chosen by individuals (Atkinson and Feather, 1966) or groups (Zander, 1968), are not the only sources of incentives among members of a United Fund board. The unreasonably difficult goals chosen by failing Funds, as a specific illustration, do not appear to be due to fear of failure alone. The needs of the community and various forms of social pressure also have a part in generating the large discrepancy between level of performance and subsequent aspiration level. We need therefore to develop ways of explaining the resultant effect of multiple incentives. In contrast to usual assumptions about the need for achievement, moreover, the members' degree of desire to achieve group success may very well change when the performance of the organization changes-this desire in short is probably not an enduring and stable disposition.

Members of the board in a United Fund react to failure in such a way that the efficiency of the organization doubtless suffers, which in turn increases the likelihood of further failure. The increased ineptness of the organization, if it is found to occur in subsequent research, requires that we modify theories of aspiration setting so that we can predict the effects of success or failure on subsequent performance. The simple formulation of the cycle: group performance, goal setting, performance, goal setting, and so on, needs to be expanded in ways that include the affect-laden reactions and apparent dysfunctional behavior of members after failure.

\section{REFERENCES}

Atrinson, J., and Feather, N. A theory of achievement motivation. New York: Wiley, 1966.

Madow, H., AND ZaNDER, A. Aspirations for the group chosen by central and peripheral members. Journal of Personality and Social Psychology, 1965, 1, 224-228.

Pepirone, E. Responsibility to the Group and its Effects on the Performance of Members. Unpublished doctoral dissertation, The University of Michigan, 1952.

ZaNder, A., AND Newcomb, T. M., Jr. Group levels of aspiration in United Fund campaigns. Journal of Personality and Social Psychology, 1967, 6, 157-162.

Zander, A. Group aspirations. In D. Cartwright and A. Zander (Eds.), Group dynamics research and theory, New York: Harper \& Row, 1968.

Zander, A., AND Forward, J. Position in group, achievement motivation, and group aspirations. Journal of Personality and Social Psychology, 1968, 8, 282-288.

RECEIVED: June 24, 1968 